\title{
AbSORÇÃo, TranslocaçÃo e ExSUdAÇÃo RAdicular de GlyPHOSATE em Clones de Eucalipto ${ }^{1}$
}

\author{
Absorption, Translocation and Radicular Glyphosate Exudation in Eucalyptus sp. Clones
MACHADO, A.F.L. ${ }^{2}$, FERREIRA, L.R. ${ }^{3}$, SANTOS, L.D.T. ${ }^{4}$, SANTOS, J.B. ${ }^{5}$, FERREIRA, F.A. ${ }^{3}$ e VIANA, R.G. ${ }^{2}$

\begin{abstract}
RESUMO - Objetivou-se com este trabalho avaliar a absorção, translocação e exsudação radicular de glyphosate por dois clones de eucalipto: 2277 e 531 . O ${ }^{14} \mathrm{C}$-glyphosate foi aplicado na concentração de $1.440 \mathrm{~g} \mathrm{ha}^{-1}$, distribuída uniformemente no terceiro e no quarto limbo foliar a partir do ápice caulinar, com radioatividade aproximada de 0,030 $\mu \mathrm{Ci}$. A absorção, translocação e exsudação radicular foram avaliadas pela radioatividade do ${ }^{14} \mathrm{C}$-glyphosate nos diferentes tecidos da planta, bem como na água de lavagem e solução nutritiva, nos intervalos de $0,2,8,32$ e 72 horas após a aplicação - HAA. A concentração de ${ }^{14} \mathrm{C}$-glyphosate na folha aplicada foi semelhante para os dois clones nas avaliações a partir de 8 HAA. Todavia, considerando a planta inteira, ela foi superior no clone 2277 em todas as épocas de avaliação. Maior quantidade de ${ }^{14} \mathrm{C}$-glyphosate foi verificada na água de lavagem da folha aplicada do clone 531, indicando menor absorção do herbicida nesse clone em relação ao 2277. Na parte aérea e no sistema radicular, a concentração do ${ }^{14} \mathrm{C}$-glyphosate foi semelhante entre os clones em todos os intervalos de avaliação, porém com concentrações maiores nas raizes. Pequena parte do total aplicado foi exsudada para solução nutritiva (valores entre 0,78 e 1,16\%), não havendo diferença entre os clones quanto à translocação na planta e na exsudação radicular do herbicida. A absorção diferencial entre os clones, atribuída na maioria dos casos a diferenças na estrutura e composição da cutícula, pode ser uma possivel explicação para a tolerância diferencial entre os genótipos.
\end{abstract}

Palavras-chave: Eucalyptus sp., herbicida, tolerância.

\begin{abstract}
To evaluate absorption, translocation and radicular glyphosate exudation in two Eucalyptus sp. clones (2277 and 531), ${ }^{14} \mathrm{C}$-glyphosate at $1440 \mathrm{~g} \mathrm{ha}^{-1}$ were distributed on the third and fourth leaf blade, under $0,030 \mu$ Ci of radioactivity. Evaluations were performed $0,2,8$, 32 and 72 hours after herbicide application-HAA. After 8 HAA, ${ }^{14} \mathrm{C}$-glyphosate on the leaf was similar in both clones. However, considering the whote plant, it was higher in 2277, at any evaluation time. After washing the leaves, higher amount of ${ }^{14} \mathrm{C}$-glyphosate was verified in the water of 531, indicating its smaller herbicide absorption. In the ground tissue and in the roots, ${ }^{14} \mathrm{C}$-glyphosate was similar in both clones, at any application time though, showing higher concentrations in the roots. Between 0.78 and $1.16 \%$ any of the applied herbicide was exuded into the nutritive solution, without showing difference on translocation and radicular exudation in both clones. The different absorption between the clones can be a likely explanation for the the different tolerance among genotypes.
\end{abstract}

Keywords: Eucalyptus sp., herbicide, tolerance.

Recebido para publicação em 8.9.2008 e na forma revisada em 21.8.2009.

2 Doutorando do Dep. de Fitotecnia da Universidade Federal de Viçosa - DFT/UFV, 36570-000 Viçosa-MG, <aroldomachado@yahoo.com.br>; ${ }^{3}$ D.Sc., Professor do Dep. de Fitotecnia - DFT/UFV; ${ }^{4}$ D.Sc., Professor do Instituto de Ciências Agrárias da Universidade Federal de Minas Gerais - UFMG, 39404-006 Montes Claros-MG; ${ }^{5}$ D.Sc., Professor do Centro de Ciências Agrárias da Universidade Federal dos Vales do Jequitinhonha e Mucuri - UFVJM, 39100-000 Diamantina-MG.

Planta Daninha, Viçosa-MG, v. 27, n. 3, p. 549-554, 2009 


\section{INTRODUÇÃO}

No manejo químico de espécies infestantes na cultura do eucalipto, o herbicida glyphosate merece destaque, por ser usado na grande maioria dos plantios comerciais dessa cultura. Por se tratar de um herbicida não seletivo ao eucalipto, sua aplicação é feita de forma dirigida, evitando-se atingir a cultura. Todavia, apesar dos cuidados na aplicação, é comum a ocorrência de deriva, causando intoxicação à cultura, o que pode acarretar prejuízos no desenvolvimento do eucalipto ou mesmo redução do estande, devido à morte de plantas mais jovens (Tuffi Santos, 2005a; Tuffi Santos et al., 2007).

Os sintomas de intoxicação pelo glyphosate em plantas de eucalipto caracterizam-se por cloroses foliares, evoluindo em alguns casos para necrose, enrolamento das folhas e superbrotação (Tuffi Santos et al., 2005a).

Trabalhos na literatura reportam os efeitos do glyphosate em plantas de eucalipto, ressaltando as diferenças de tolerância entre genótipos (Tuffi Santos et al., 2006, 2007). Entretanto, os processos envolvidos com a tolerância diferencial ao glyphosate, bem como seu comportamento no interior da planta, não estão bem elucidados. Acredita-se que a diferença de sensibilidade entre genótipos de eucalipto ao glyphosate possa ser atribuída a diferenças na absorção, translocação, compartimentalização, exsudação radicular e ao metabolismo da molécula herbicida (Vargas et al., 1999).

A absorção de herbicidas pela planta envolve a penetração inicial através da cutícula e a absorção simplástica, sendo a duração desse processo dependente da espécie envolvida, da idade da planta, das condições ambientais e da concentração do herbicida e do surfatante (Silva et al., 2007). Após a absorção, é necessária a translocação do herbicida, através de tecidos vasculares, até os sítios de ação, onde ele vai exercer sua atividade (Satichivi et al., 2000).

Objetivou-se neste trabalho avaliar a absorção, translocação e exsudação radicular de glyphosate em clones de eucalipto.

\section{MATERIAL E MÉTODOS}

Mudas de dois clones de Eucalyptus grandis (531 e 2277) foram cultivadas em ambiente protegido, em vasos contendo 0,2 L de solução nutritiva de Clark, modificada e aerada artificialmente. Cada vaso com uma planta de eucalipto foi considerado uma unidade experimental.

Doze dias após o transplantio das mudas, aplicou-se o ${ }^{14} \mathrm{C}$-glyphosate em mistura à formulação comercial de glyphosate (Scout $\mathbb{R}$ ). Na aplicação, utilizou-se uma microsseringa de precisão, em que $100 \mu \mathrm{L}$ de calda contendo o ${ }^{14} \mathrm{C}$-glyphosate (radioatividade de aproximadamente $0,030 \mu \mathrm{Ci}$ ), correspondendo a $1.440 \mathrm{~g} \mathrm{ha}^{-1}$ de glyphosate, foram espalhados uniformemente em folhas totalmente expandidas do terceiro e quarto nós a partir do ápice caulinar.

A absorção, translocação e exsudação radicular foram avaliadas pela radioatividade do ${ }^{14} \mathrm{C}$-glyphosate, nos intervalos de $0,2,8,32$ e 72 horas após a aplicação do herbicida HAA. As plantas foram coletadas e fracionadas em ápice principal, folhas que receberam aplicação, demais folhas e raízes em todas as épocas de avaliação. Após cada coleta, as folhas que receberam aplicação foram lavadas com 9,0 mL de metanol, para extração do produto não absorvido. Após a separação e identificação, todas as partes da planta foram acondicionadas em sacos de papel e secas em estufa a $50{ }^{\circ} \mathrm{C}$, por 48 horas, para determinação da massa seca. Após a secagem, procedeu-se à moagem, em moinho de bola, até apresentarem textura equivalente a 200 mesh. Amostras do material moído de aproximadamente $100 \mathrm{mg}$ de cada componente das plantas foram adicionadas em frascos de contagem de $20 \mathrm{~mL}$, acrescentando-se $1 \mathrm{~mL}$ de Triton-X-100 ${ }^{\circledR}$, sob agitação em vórtex por aproximadamente 14 segundos. Em seguida, foram adicionados $5 \mathrm{~mL}$ do coquetel de cintilação (Sigma Flúor, contendo $30 \mathrm{~g}$ de cab-o-sil), com posterior homogeneização. Após essa etapa, as amostras foram avaliadas em espectrômetro de cintilação líquida Beckman 6500, o qual corrigia o quenching automaticamente para efetuar as determinações de radioatividade. 
Os valores da radiação (CPM total) encontrados na solução de lavagem, na solução nutritiva e nas partes das plantas foram expressos em porcentagem em relação à radiação total aplicada. A radioatividade encontrada nas folhas que receberam herbicida, no ápice caulinar, no restante das folhas e nas raízes foi expressa em porcentagem de ${ }^{14} \mathrm{C}$-glyphosate em relação ao total presente na planta.

\section{RESULTADOS E DISCUSSÃO}

A quantidade de ${ }^{14} \mathrm{C}$-glyphosate presente na solução de lavagem das folhas tratadas foi maior no clone $531 \mathrm{em}$ todas as épocas de avaliação (Figura 1), indicando que a taxa de absorção do herbicida foi inferior neste, em comparação com o 2277. Em ambos os clones houve redução acentuada na quantidade de herbicida removida pela água de lavagem das folhas aplicadas nas primeiras $8 \mathrm{HAA}$, indicando rápida absorção nesse período. Verificou-se também redução da concentração do herbicida na água de lavagem no intervalo de 8 a 72 HAA (Figura 1).

As taxas de absorção foliar de herbicidas e, consequentemente, sua eficácia estão diretamente relacionadas aos tipos de estrutura foliar e à permeabilidade da cutícula (Baker, 1982), que dependem da constituição e da polaridade dos componentes cuticulares. O glyphosate tem baixo Kow, apresentando pouca afinidade a lipídios (Kirkwood, 1999); as ceras

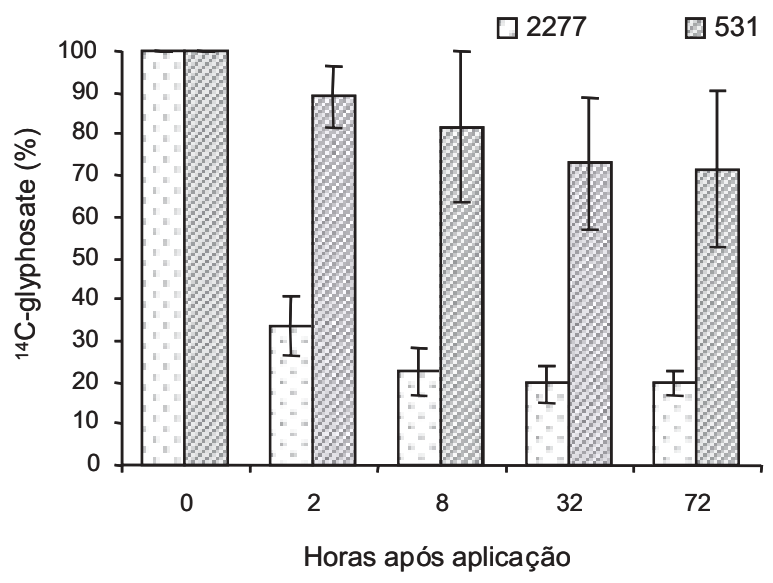

Figura 1 - Porcentagem de ${ }^{14} \mathrm{C}$-glyphosate na solução de lavagem, em relação ao total aplicado. epicuticulares com grande quantidade de compostos apolares podem constituir barreira à penetração desse herbicida. A difusão do glyphosate pela cutícula de cinco espécies, estudada por Subramaniam \& Hoggard (1988), foi considerada baixa, sendo rapidamente melhorada após a extração da cera epicuticular. Estes autores relataram que para produtos hidrofilicos, como o glyphosate, as ceras não são a principal barreira à difusão de herbicidas. Por sua vez, a matriz de polímeros que constitui a cutina seria a barreira mais significativa à difusão do glyphosate através da cutícula.

Em relação ao ${ }^{14} \mathrm{C}$-glyphosate presente nas folhas que receberam aplicação, observou-se acúmulo semelhante entre os dois clones, com diferença apenas com 2 HAA, em que o clone 2277 apresentou maior concentração (Figura 2). Os resultados estão de acordo com os de Monqueiro et al. (2004), que avaliaram a absorção e translocação do ${ }^{14} \mathrm{C}$-glyphosate nas espécies Commelina benghalensis, Ipomoea grandifolia e Amaranthus hybridus, concluindo que o herbicida se acumulava na folha aplicada em quantidades diferenciadas nas espécies, indicando absorção diferencial como provável mecanismo de tolerância. O acúmulo de ${ }^{14} \mathrm{C}$-diuron na folha tratada de duas espécies de capim-colchão (Digitaria insularis e D. nuda) também foi verificado por Dias et al. (2003).

Duas horas após a aplicação do ${ }^{14} \mathrm{C}$-glyphosate, observou-se que ele já havia



Figura 2 - Porcentagem de ${ }^{14} \mathrm{C}$-glyphosate na folha de aplicação, em relação ao total encontrado na planta.

Planta Daninha, Viçosa-MG, v. 27, n. 3, p. 549-554, 2009 
se distribuído pela parte aérea das plantas, em concentração semelhante (cerca de $42 \%$ do total presente na planta). Na avaliação aos 72 HAA, os valores observados foram de 53,31 e $55,79 \%$ nos clones 2277 e 531 , respectivamente (Figura 3). Em todas as épocas de avaliação a concentração de ${ }^{14} \mathrm{C}$-glyphosate na parte aérea foi semelhante entre os clones avaliados (Figura 3). O movimento do glyphosate na planta está associado ao fluxo de carboidratos de órgãos tidos como fontes para os drenos metabólicos, ocasionando o acúmulo desse herbicida nos ápices e em raízes (McAllister \& Haderlie, 1985).

No sistema radicular encontrou-se maior concentração de ${ }^{14} \mathrm{C}$-glyphosate que na parte aérea. Duas horas após a aplicação, 51,72 e $57,38 \%$ de todo o herbicida presente nas plantas foram detectados no sistema radicular dos clones 2277 e 531, respectivamente (Figura 4). A velocidade de translocação do glyphosate para as raízes está associada ao transporte de açúcares no floema, que é rápido e, em geral, pode variar de 0,3 a $1,5 \mathrm{~m} \mathrm{~h}^{-1}$ (Taiz $\&$ Zeiger, 2004). Nos dois clones, a concentração do ${ }^{14} \mathrm{C}$-glyphosate ao longo do tempo nas raízes foi semelhante (Figura 4 ).

Baixas concentrações de ${ }^{14} \mathrm{C}$-glyphosate, em relação ao aplicado, foram encontradas na solução nutritiva, tanto no clone 2277 quanto no 531 (Figura 5). Esse resultado indica que pequena quantidade do ${ }^{14} \mathrm{C}$-glyphosate aplicado, entre 0,78 e $1,16 \%$, foi exsudada pelo sistema radicular ao meio de cultivo. O glyphosate pode ser liberado para o solo através da exsudação radicular ou da morte e extravasamento celular de tecidos de plantas tratadas com esse herbicida. É provável que as concentrações de ${ }^{14} \mathrm{C}$-glyphosate encontradas sejam provenientes da exsudação radicular, dado o curto espaço de tempo para ocorrência de morte dos tecidos das raizes (Figura 5).

Alguns autores relatam a exsudação do glyphosate em cultivos celulares (Hetherington et al., 1998) e os efeitos do produto exsudado em plantas adjacentes, que compartilham a mesma zona radicular de plantas tratadas (Coupland \& Lutman, 1982). Rodrigues et al. (1982) comprovaram a exsudação radicular de ${ }^{14} \mathrm{C}$-glyphosate por plantas de trigo que receberam a aplicação desse herbicida nas folhas.

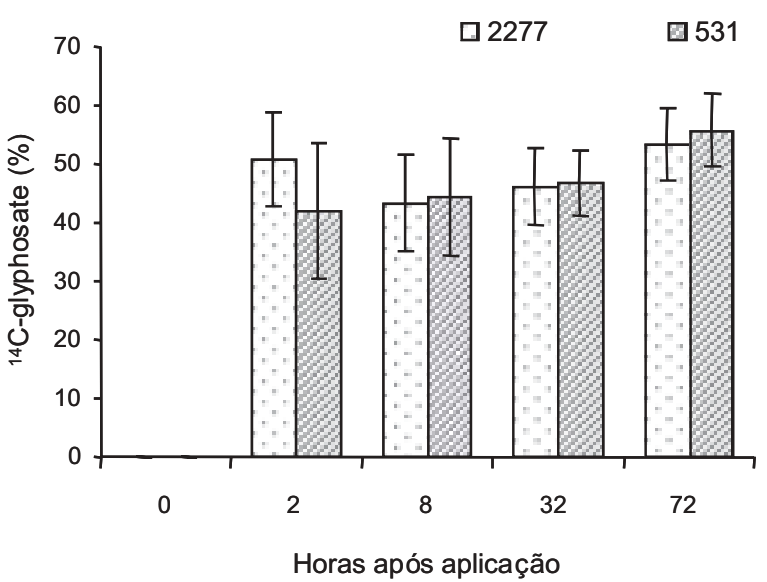

Figura 3 - Porcentagem de ${ }^{14} \mathrm{C}$-glyphosate na parte aérea, em relação ao total encontrado na planta.

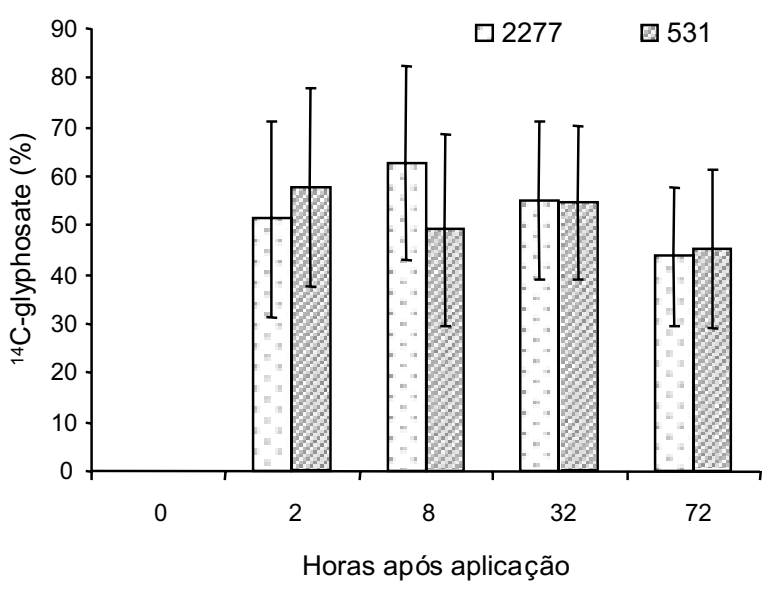

Figura 4 - Porcentagem de ${ }^{14} \mathrm{C}$-glyphosate no sistema radicular, em relação ao total encontrado na planta.

Adicionalmente, estes autores encontraram em plantas de milho cultivadas próximo ao trigo o ${ }^{14} \mathrm{C}$-glyphosate, que foi absorvido pelas raízes e distribuído por todas as partes da planta. Tuffi Santos et al. (2005b) relatam a inexistência de sintomas de intoxicação nas plantas de eucalipto cultivado em consórcio com braquiária, em sistema hidropônico e em solo. Segundo estes autores, a possivel exsudação do glyphosate pelas plantas de braquiária ocorreu em concentrações inferiores às necessárias para provocar injúrias ao eucalipto.

Em condições de campo, o glyphosate exsudado por plantas de eucalipto intoxicadas 
ou tratadas com glyphosate - no caso do controle da rebrota das cepas - é rapidamente adsorvido pelos coloides do solo (Glass, 1987; Shoval \& Yariv, 1979), tornando-se menos disponivel à solução do solo e à reabsorção por plantas. Segundo Santos et al. (2005), existe efeito tóxico do exsudado de glyphosate sobre microrganismos de solo associados às plantas, e a intoxicação desses microrganismos é variável em função da marca comercial utilizada.

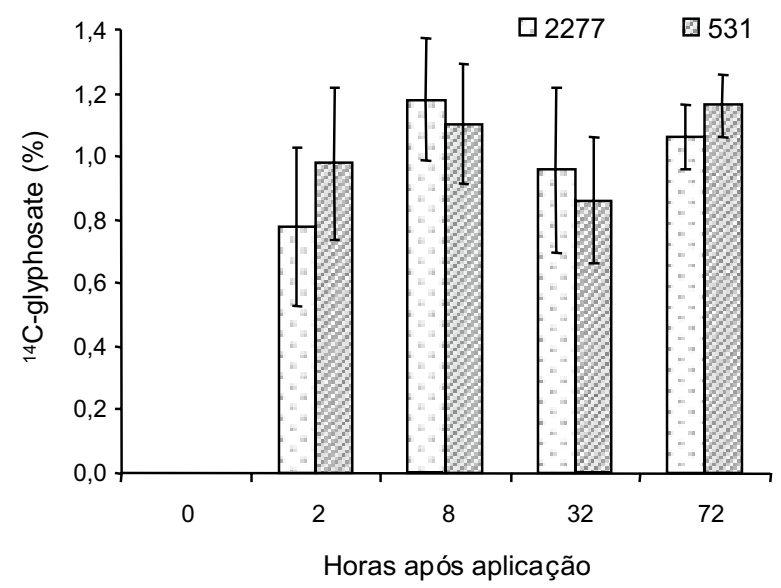

Figura 5 - Porcentagem de ${ }^{14} \mathrm{C}$-glyphosate na solução nutritiva, em relação ao total aplicado.

A quantidade de ${ }^{14} \mathrm{C}$-glyphosate presente na planta foi superior no clone $531 \mathrm{em}$ todas as épocas de avaliação (Figura 6). As maiores concentrações observadas do herbicida nas plantas foram com 8 HAA no clone 2277 (8,28\%) e com 32 HAT no clone 531 (10,07\%). Com 72 HAT nos clones 2277 e 531, apenas 5,02 e $8,04 \%$, respectivamente, do ${ }^{14} \mathrm{C}$-glyphosate aplicado foram encontrados nas plantas, indicando diminuição das concentrações do produto, que pode ser atribuída, em parte, à exsudação radicular.

Não houve diferença entre os genótipos na translocação na planta e na exsudação radicular do herbicida. Por outro lado, maior absorção foi observada no clone 2277, sendo possivel explicação para a tolerância diferencial entre genótipos. Contudo, novos trabalhos sobre a superficie foliar, principalmente sobre a estrutura e constituição da cutícula, bem como sobre o metabolismo do herbicida

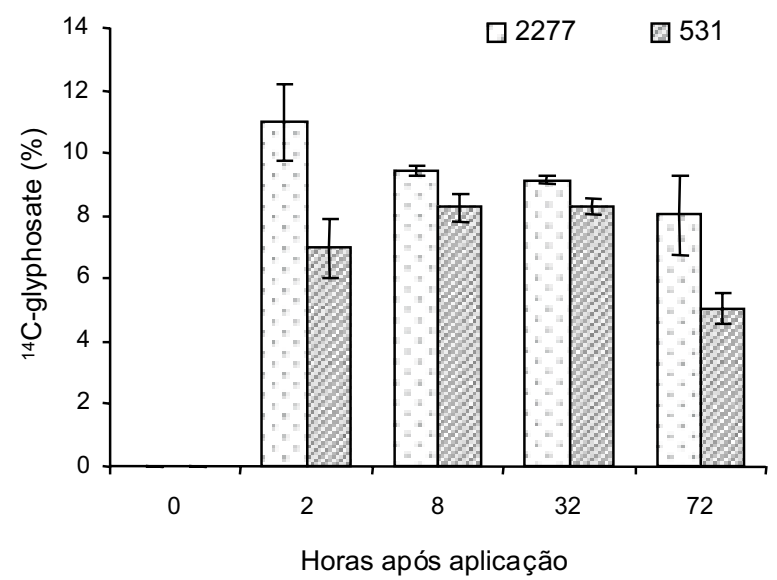

Figura 6 - Quantidade de ${ }^{14} \mathrm{C}$-glyphosate na planta, em porcentagem do total aplicado.

pelos diferentes clones, devem ser realizados para elucidar o comportamento do glyphosate em plantas de eucalipto.

\section{LITERATURA CITADA}

BAKER, E. A. Chemistry and morphology of plant epicuticular waxes. In: CUTLER, D. F.; ALVIN, K. L.; PRICE, C. E. (Eds.). The plant cuticle. London: Academic Press, 1982. p. 140-161.

COUPLAND, D.; LUTMAN, P. Investigations into the movement of glyphosate from treated to adjacent untreated plants. Ann. Appl. Biol., v. 101, n. 2, p. 315-321, 1982.

DIAS, N. M. P. et al. Absorção e translocação do herbicida Diuron por espécies susceptível e tolerante de capim-colchão (Digitaria spp.). Planta Daninha, v. 21, n. 2, p. 293-300, 2003.

GLASS, R. L. Adsorption of glyphosate by soils and clay minerais. J. Agric. Food. Chem., v. 35, n. 2, p. 497-500, 1987.

HETHERINGTON, P. et al. The absorption, translocation and distribution of the herbicide glyphosate in maize expressing the CP-4 transgene. J. Exp. Bot., v. 50, n. 339, p. $1567-1576,1998$.

KIRKWOOD, R. C. et al. Absortion, localization, translocation and activity of glyphosate in barnyardgrass (Echinochloa crus-galli (L) Beauv): influence of herbicide and surfactant concentration. Pest Manag. Sci., v. 56, n. 4, p. 359-367, 1999. 
MCALLISTER, R.; HABERLIE, L. L. Translocation of ${ }^{14} \mathrm{C}$-glyphosate and ${ }^{14} \mathrm{CO}_{2}$-labeled photoasimilates in Canada thistle (Cirsium arvense). Weed Sci., v. 33, n. 2, p. 153-159, 1985.

MONQUEIRO, P. A. et al. Absorção, translocação e metabolismo do glyphosate por plantas tolerantes e susceptíveis a estes herbicidas. Planta Daninha, v. 22, n. 3, p. 123-132, 2004.

RODRIGUES, J. F. V:; WORSHAM, A. D.; CORBIN, F. T. Exudation of glyphosate from wheat (Triticum aestivum) plants and its effects on interplanted corn (Zea mays) and soybeans (Glycine max). Weed Sci., v. 30, n. 3, p. 316-320, 1982.

SATICHIVI, N. M. et al. Absorption and translocation of glyphosate isopropylamine and trimethysulfonium salts in Abutilon theophrasti and Setaria faberi. Weed Sci., v. 48, n. 6, p. $675-679,2000$.

SHOVAL, S.; YARIV, S. Adsorption of glyphosate in the soil. Clay. Clay Miner., v. 27, n. 1, p. 19-28, 1979.

SANTOS, J. B. et al. Tolerance of Bradyrhizobium strains to glyphosate formulations. Crop Prot., v. 24, n. 6, p. 543-547, 2005.
SILVA, J. F. et al. Herbicida: absorção, translocação, metabolismo, formulação e misturas. In: SILVA, A. A.; SILVA, J. F. Tópicos em manejo de plantas daninhas. Viçosa, MG: Universidade Federal de Viçosa, 2007. 367 p

SUBRAMANIAM, V.; HOGGARD, P. E. Metal complexes of glyphosate, J. Agric. Food Chem., v. 36, p. 1326-1329, 1988.

TAIZ, L.; ZEIGER, E. Fisiologia vegetal. 3.ed. São Paulo: Artmed, 2004. 719 p.

TUFFI SANTOS, L. D. et al. Crescimento e morfoanatomia foliar de eucalipto sob efeito de deriva do glyphosate. Planta Daninha, v. 23, n. 1, p. 133-142, 2005a.

TUFFI SANTOS, L. D. et al. Exsudação radicular do glyphosate por Brachiaria decumbens e seus efeitos em plantas de eucalipto e na respiração microbiana do solo Planta Daninha, v. 23, n. 1, p. 143-152. 2005b.

TUFFI SANTOS, L. D. et al. Características da epiderme foliar de eucalipto e seu envolvimento com a tolerância ao glyphosate. Planta Daninha, v. 24, n. 2, p. 513-520, 2006.

TUFFI SANTOS, L. D. et al. Morphological responses of different eucalypt clones submitted to glyphosate drift. Environ. Exp. Bot., v. 59, n. 1, p. 11-20, 2007. 